\title{
Implementasi Fuzzy Associative Memory (FAM) Dalam Sistem Pendukung Keputusan Untuk Penentuan Kepuasan Pasien BPJS Kesehatan Terhadap Pelayanan (RSU) Martha Friska Multatuli Medan
}

\author{
Tugiono, Maldarisa Kharisma Situmorang, “Azlan \\ Program Studi Sistem Informasi, STMIK Triguna Dharma \\ Jl. A.H Nasution No.73 Medan, Indonesia, 20142 \\ E-mail: azlansaja19gmail.com
}

\begin{abstract}
Abstrak
Rumah sakit adalah sarana penyedia jasa pelayanan kesehatan bagi masyarakat. RSU. Martha Friska Multatuli Medan merupakan salah satu rumah sakit swasta yang menyediakan pelayanan kesehatan kepada masyarakat dengan penjaminan Umum, BPJS Kesehatan, Perusahaan dan Asuransi. Agar dapat bertahan dan berkembang dengan baik, maka RSU. Martha Friska Multatuli Medan harus dapat menciptakan kemampuan bersaing yang baik, terutama dalam hal pelayanan medis, pelayanan administrasi dan kenyamanan, sehingga dapat memenangkan persaingan. Diantara cara yang dapat digunakan untuk mengetahui sejauh mana kualitas pelayanan yang diberikan terhadap pasien adalah dengan informasi penilaian kepuasan pasien. Untuk itu dibutuhkan sebuah sistem yang dapat digunakan dalam mengolah data penilaian pasien. Salah satu sistem yang dapat dibangun adalah sistem pendukung keputusan dengan menggunakan metode Fuzzy Associative Memory (FAM). Sistem Pendukung Keputusan merupakan sistem berbasis komputer yang dipakai untuk mendukung pengambilan keputusan dalam suatu organisasi, instansi ataupun perusahaan. FAM adalah metode pengambilan keputusan yang fleksibel, merupakan suatu sistem fuzzy yang memetakan himpunan fuzzy ke himpunan fuzzy lainnya.
\end{abstract}

Kata Kunci: Sistem Pendukung Keputusan, Fuzzy Associative Memory, Tingkat Kepuasan

\begin{abstract}
The hospital is a means of providing health services to the community. RSU. Martha Friska Multatuli Medan is one of the private hospitals that provides health services to the public with public guarantees, BPJS Health, Companies and Insurance. In order to survive and develop properly, the RSU. Martha Friska Multatuli Medan must be able to create a good competitive ability, especially in terms of medical services, administrative services and comfort, so as to win the competition. Among the ways that can be used to determine the extent to which the quality of services provided to patients is with information on assessing patient satisfaction. For that we need a system that can be used in processing patient assessment data. One system that can be built is a decision support system using the Fuzzy Associative Memory (FAM) method. Decision Support System is a computer-based system that is used to support decision making in an organization, agency or company. FAM is a flexible decision-making method, it is a fuzzy system that maps fuzzy sets to other fuzzy sets.
\end{abstract}


Keywords: Decision Support System, Fuzzy Associative Memory, Level of Satisfaction I. PENDAHULUAN

Rumah sakit adalah sarana penyedia jasa pelayanan kesehatan bagi masyarakat. RSU. Martha Friska Multatuli Medan merupakan salah satu rumah sakit swasta yang menyediakan pelayanan kesehatan kepada masyarakat dengan penjaminan Umum, BPJS Kesehatan, Perusahaan dan Asuransi. Agar dapat bertahan dan berkembang dengan baik, maka RSU. Martha Friska Multatuli Medan harus dapat menciptakan kemampuan bersaing yang baik, terutama dalam hal pelayanan medis, pelayanan administrasi dan kenyamanan, sehingga dapat memenangkan persaingan.

Diantara cara yang dapat digunakan untuk mengetahui sejauh mana kualitas pelayanan yang diberikan terhadap pasien adalah dengan informasi penilaian kepuasan pasien. Adapun saat ini, untuk mendapatkan informasi tentang penilaian kepuasan pasien, pihak rumah sakit hanya mengandalkan cara manual, yaitu dengan penerimaan kritik dan saran tertulis dari pasien. Hal ini tentu tidak efektif dan efisien. Untuk itu dibutuhkan sebuah sistem yang dapat mengolah data penilaian kepuasan pasien berbasis komputer yang efektif dan efisien.

Salah satu sistem yang bisa digunakan untuk penilaian kepuasan pasien adalah Sistem Pendukung Keputusan dengan Metode Fuzzy Associative Memory. Sistem Pendukung Keputusan (SPK) merupakan suatu sistem informasi spesifik yang ditujukan untuk membantu manajemen dalam mengambil keputusan yang berkaitan dengan persoalan yang bersifat semi terstruktur [1]. Sistem Pendukung Keputusan merupakan sistem berbasis komputer yang dipakai untuk mendukung pengambilan keputusan dalam suatu organisasi, instansi ataupun perusahaan. Metode Fuzzy Associative Memory (FAM) merupakan salah satu algoritma yang ada pada logika fuzzy. FAM adalah metode pengambilan keputusan yang fleksibel, merupakan suatu sistem fuzzy yang memetakan himpunan fuzzy ke himpunan fuzzy lainnya [2].

\section{METODE PENELITIAN}

Metedologi penelitian adalah cara kerja pikir dalam memahami suatu objek, yang didalamnya terdapat cara bagaimana mengisi atau melakukan hasil dari pemahaman tersebut. Metode penelitian yang menyangkut dalam pengumpulan data dilakukan dengan cara :

1. Teknik Observasi

Observasi adalah teknik pengumpulan data dengan penelitian dan peninjauan lapangan terhadap permasalahan yang diambil dari RSU. Martha Friska Multatuli Medan tentang Sistem Pendukung Keputusan menggunakan metode Fuzzy Asocciative Memory (FAM).

2. Teknik Wawancara

Pada tahap ini pengumpulan data yang dilakukan dengan cara berkomunikasi langsung dengan pasien untuk mengambil hak angket.

3. Teknik Perpustakaan

Pada tahap ini dilakukan pengumpulan data dengan mencari berbagai buku, jurnal dan modul yang berkaitan dengan Sistem Pendukung Keputusan, metode Fuzzy Asocciative Memory (FAM) dan Visual Basic.

4. Teknik Perancangan

Pada tahap ini dilakukan perancangan algoritma sistem, perancangan flowchart program, perancangan pemodelan sistem, perancangan sistem, dan perancangan interface.

5. Teknik Pengujian

Pada tahap ini dilakukan rangkaian uji coba untuk mendeteksi kesalahan dan memvalidasi logika dalam program secara bersamaan. 


\section{ANALISIS DAN HASIL}

Permasalahan yang muncul pada saat dilakukannya penentuan tingkat kepuasan pelayanan adalah sering kali pimpinan sebagai pengambil keputusan masih mengandalkan intuisi (subjektif). Hal ini tentu saja menjadi sebuah kekurangan untuk menentukan tingkat kepuasan perawatan pada pasien yang datang dan menggunakan jasa kesehatan pada RSU. Martha Friska Multatuli Medan. Oleh Karena itu, untuk menentukan tingkat kepuasan konsumen digunakanlah logika fuzzy dalam pengambilan keputusan.

Penelitian ini akan membahas tentang mengenai penentuan kepuasan pasien rawat inap dengan metode Fuzzy Associative Memory berdasarkan data pasien yang datang dan menggunakan jasa kesehatan dengan proses yang tepat dan akurat.

Dengan menggunakan metode Fuzzy Associative Memory akan ditentukan faktor - faktor yang saling berhubungan dalam menentukan tingkat kepuasan pasien. Pada Fuzzy Associatve Memory sederhana akan memetakan suatu aturan fuzzy himpunan pasangan ( $\left.A \_i, B \_j\right)$ yang menghubungkan himpunan fuzzy $B$ j kehimpunan fuzzy $A \_i$. Untuk ini penelitian ini diangkat agar dapat menyelesaikan permasalahan dalam menentukan kepuasan pasien dengan faktorfaktor yang saling berkaitan yang diatur dengan metode FAM.

1. Algoritma Sistem

Terdapat 4 tahap Algoritma Fuzzy Assosiative Memory (FAM) adalah sebagai berikut :

- Mengkodekan input dan output kedalam FAM matrix $\{(\mathrm{Ai}, \mathrm{Bi}) \mid 0<=\mathrm{i}<\mathrm{m}\}$ dimana $\mathrm{m}$ adalah jumlah data.

- Menghitung auto associative fuzzy Hebbian FAM matriks dengan salah satu dari dua aturan pembelajaran, yaitu dengan correlation-minimum encoding atau dengan correlation product encoding.

- Apabila nilai M sudah didapat, nilai B bisa dicari dengan melakukan relasi komposisi dari $A$ dan $M$. kita juga bias mencari nilai $A$ dengan melakukan relasi komposisi dari $B$ dan M. Relasi komposisi bisa dilakukan dengan max-min composition atau dengan max-product composition.

- prosesdefuzzy dengan menggunakan aturan winner take all atau dengan weighted average.

Untuk itu, maka masing-masing variabel fuzzy beserta batasan nilai input untuk setiap himpunan input dan output dapat dilihat pada gambar berikut.

a. Tingkat Penilaian Pelayanan Medis

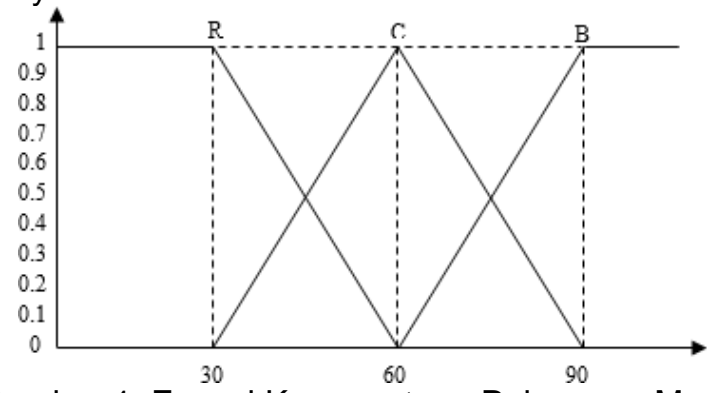

Gambar 1. Fungsi Keanggotaan Pelayanan Medis

$\mathrm{R}$ merupakan himpunan fuzzy dengan nilai Buruk dengan nilai himpunan yaitu $30 \mathrm{C}$ merupakan himpunan fuzzy dengan nilai Cukup dengan nilai himpunan yaitu $60 \mathrm{~B}$ merupakan himpunan fuzzy dengan nilai Baik dengan nilai himpunan yaitu 9 .

J-SISKO TECH Vol. 3, No. 1, $2020: 70-77$ 
b. Tingkat Peneliaian Pelayanan Administrasi

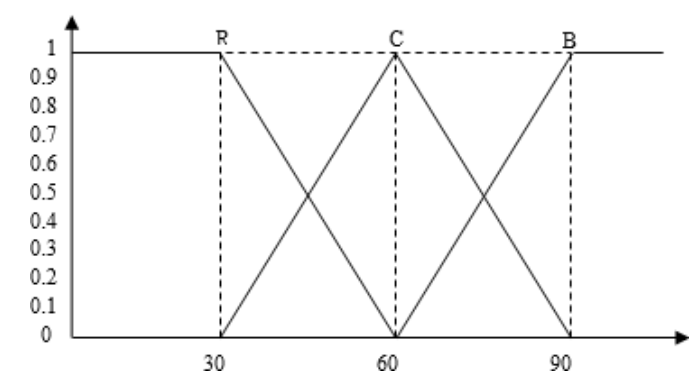

Gambar 2. Fungsi Keanggotaan Pelayanan Adminstrasi

$\mathrm{R}$ merupakan himpunan fuzzy dengan nilai Buruk dengan nilai himpunan yaitu $30 \mathrm{C}$ merupakan himpunan fuzzy dengan nilai Cukup dengan nilai himpunan yaitu $60 \mathrm{~B}$ merupakan himpunan fuzzy dengan nilai Baik dengan nilai himpunan yaitu 90

c. Tingkat Penilaian Kondisi Fasilitas

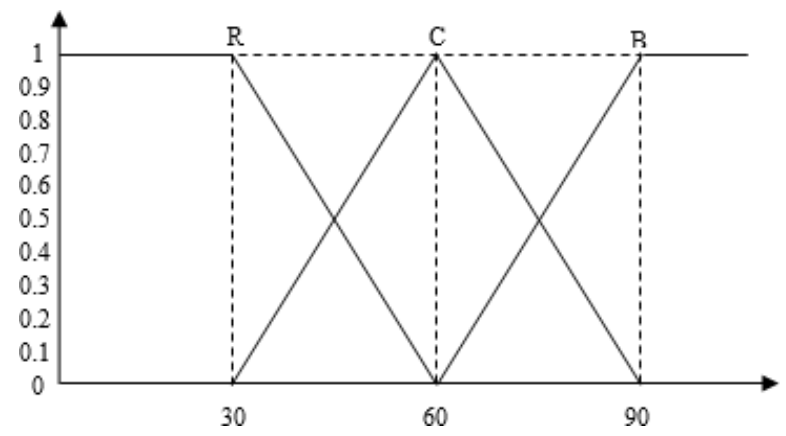

Gambar 3. Fungsi Keanggotaan Kondisi Fasilitas

$\mathrm{R}$ merupakan himpunan fuzzy dengan nilai Buruk dengan nilai himpunan yaitu $30 \mathrm{C}$ merupakan himpunan fuzzy dengan nilai Cukup dengan nilai himpunan yaitu $60 \mathrm{~B}$ merupakan himpunan fuzzy dengan nilai Baik dengan nilai himpunan yaitu 90

d. Tingkat Penilaian Kondisi Keamanan

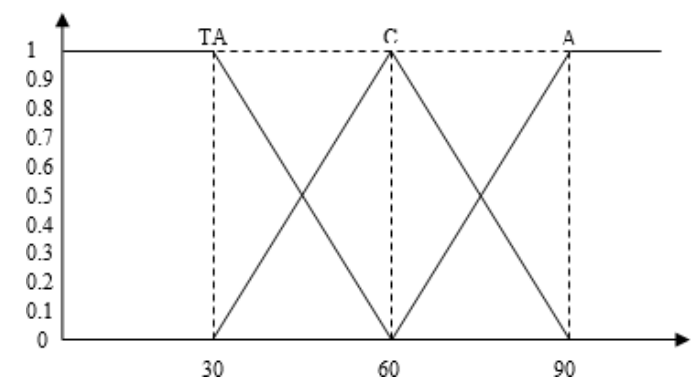

Gambar 4. Fungsi Keanggotaan Kondisi Keamanan

TA merupakan himpunan fuzzy dengan nilai Tidak Aman dengan nilai himpunan yaitu $30 \mathrm{C}$ merupakan himpunan fuzzy dengan nilai Cukup dengan nilai himpunan yaitu $60 \mathrm{~A}$ merupakan himpunan fuzzy dengan nilai Aman dengan nilai himpunan yaitu 90

Berikut ini adalah contoh soal untuk menghitung tingkat kepuasan pasien terhadap pelayanan di RSU. Martha Friska Multatuli Medan yaitu Seorang Pasien BPJS Kesehatan yang melakukan perawatan medis pada RSU. Martha Friska Multatuli Medan melakukan penilaian terhadap 
rumah sakit dengan penilaian tingkat kondisi fasilitas 50\%, tingkat keamanan $65 \%$, penilaian terhadap medis $75 \%$, dan nilai pelayanan administrasi $70 \%$, maka dengan metode FAM tingkat kepuasan pada pasien rawat inap dengan penjaminan BPJS Kesehatan ditentukan sesuai dengan algoritma metode FAM.

2. Mengkodekan Input dan Output dalam FAM Matrix

Untuk mengkodekan kumpulan fuzzy $(A, B)=((a 1, a 2, a 3 \ldots . . . a n),(b 1, b 2, b 3 . . . . b p))$ kebentuk matriks FAM secara numeris, dapat digunakan aturan pembelajaran Hebb. Ada 2 aturan pembelajaran, yaitu correlation-minimum encoding dan correlation-product encoding. Dalam penelitian ini aturan yang digunakan adalah correlation-minimum encoding ( $M=A T \circ b)$. Berdasarkan fungsi keanggotaan pada setiap masing-masing himpunan fuzzy variabel diatas maka dapat dihitung seperti dibawah ini :

1. Fungsi keanggotan pada masing-masing himpunan pelayanan medis :

a1 $=\mu$ buruk $(75)=(90-75) /(90-30)=0.25$

a2 $=\mu$ cukup $(75)=(90-75) /(90-60)=0.5$

a3 $=\mu$ baik $(75)=(75-30) /(90-30)=0.75$

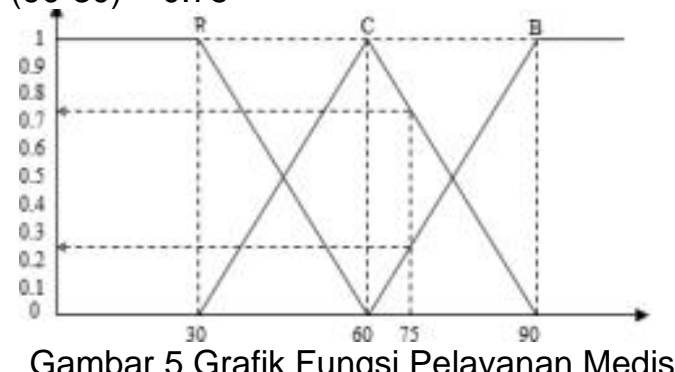

2. Fungsi keanggotan pada masing-masing himpunan pelayanan administasi :

a1 $=\mu$ buruk $(70)=(90-70) /(90-30)=0.33$

a2 $=\mu$ cukup $(70)=(90-70) /(90-60)=0.67$

a3 $=\mu$ baik $(70)=(70-30) /(90-30)=0.67$

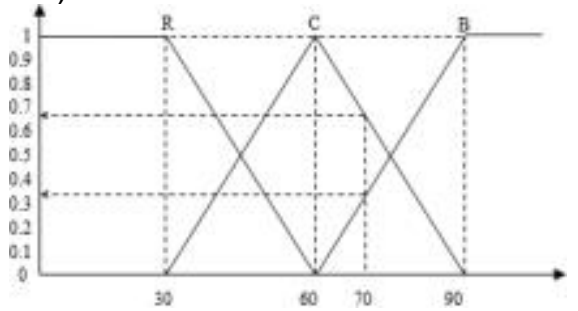

Gambar 6 Grafik Fungsi Pelayanan Administrasi

3. Fungsi keanggotan pada masing-masing himpunan kondisi fasilitas :

a1 $=\mu$ buruk $(50)=(90-50) /(90-30)=0.67$

a2 $=\mu$ cukup $(50)=(90-50) /(90-60)=1.33$

a3 $=\mu$ baik $(50)=(50-30) /(90-30)=0.33$

J-SISKO TECH Vol. 3, No. 1, $2020: 70-77$ 


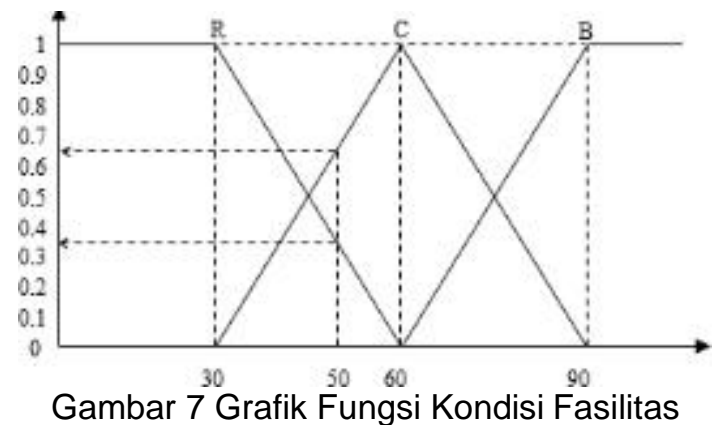

4. Fungsi keanggotan pada masing-masing himpunan kondisi keamanan :

a1 $=\mu$ tidak aman $(65)=(90-65) /(90-30)=0.42$

a2 $=\mu$ cukup $(65)=(90-65) /(90-60)=0.83$

a3 $=$ maman $(65)=(65-30) /(90-30)=0.58$

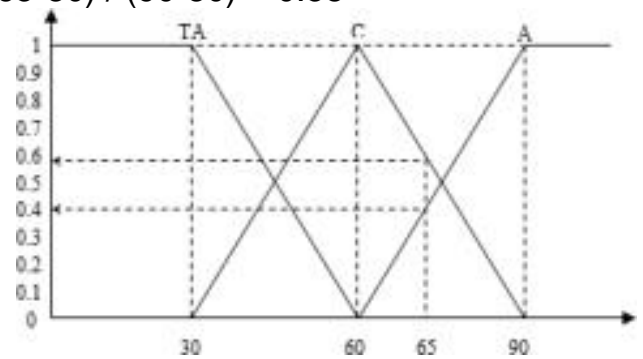

Gambar 8 Grafik Fungsi Kondisi Keamanan

3. Menghitung Auto Associative Fuzzy Hebbian FAM

Dari kasus data maka dapat diketahui nilai $A=(0.75,0.67,0.67,0.58)$ dan $B=(0.7,0.6,0.8,0.7)$, dengan demikian matriks $M$ berdasarkan correlation-product encoding dapat dilihat sebagai berikut :

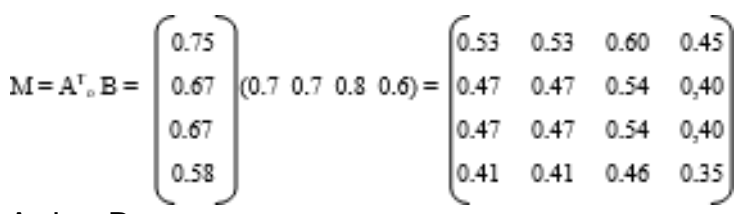

4. Relasi Komposisi A dan B

Apabila nilai matriks $M$ telah didapat, maka nilai $B$ selanjutnya dapat diperoleh dengan menggunakan relasi komposis dari $\mathrm{A}$ dan $\mathrm{M}$. Relasi komposisi yang digunakan adalah maxproduct composition. Pada max-product composition nilai $\mathrm{B}$ dapat diperoleh dengan menggunakan komposisi A o M sebagai berikut:

$$
\begin{aligned}
& \text { bj }=\max \left\{\left(\mathrm{ai}^{*} \mathrm{mij}\right)\right\} \text {, sehingga ; } \\
& \text { b1 }=\max \left\{\left(0.75^{\star} 0.53\right) ;\left(0.67^{\star} 0.47\right) ;\left(0.67^{\star} 0.47\right) ;\left(0.58^{\star} 0.41\right)\right\} \\
& =\max \{0.39 ; 0.31 ; 0.31 ; 0.24\}=0.39 \\
& \text { b2 }=\max \left\{\left(0.75^{\star} 0.53\right) ;\left(0.67^{\star} 0.47\right) ;\left(0.67^{\star} 0.47\right) ;\left(0.58^{\star} 0.41\right)\right\} \\
& =\max \{0.39 ; 0.31 ; 0.31 ; 0.24\}=0.39 \\
& \text { b3 }=\max \left\{\left(0.75^{\star} 0.60\right) ;\left(0.67^{\star} 0.54\right) ;\left(0.67^{\star} 0.54\right) ;\left(0.58^{\star} 0.46\right)\right\} \\
& =\max \{0.45 ; 0.36 ; 0.36 ; 0.26\}=0.45 \\
& \text { b4 }=\max \left\{\left(0.75^{\star} 0.45\right) ; ;\left(0.67^{\star} 0.40\right) ;\left(0.67^{\star} 0.40\right) ;\left(0.58^{\star} 0.35\right)\right\} \\
& =\max \{0.34 ; 0.27 ; 0.27 ; 0.20\}=0.34 \\
& B=0.39 ; 0.39 ; 0.45,0.34
\end{aligned}
$$




\section{Deffuzy}

Pada metode FAM, proses defuzzyfikasi dilakukan dengan 2 cara, yaitu winner take all dengan mengambil nilai tertinggi $B$ * $100 \%$ atau dengan weighted average yang bersesuaian. Sehingga dalam kasus pada penelitian ini nilai akhir untuk menentukan tingkat kepuasan pada pasien BPJS Kesehatan adalah b3 $=0.45 * 100 \%=45 \%$ (winner take all). Jika dengan weighted average dihitung dengan cara berikut :

$$
\mathrm{B}^{*}=\frac{(0.39 * 75)+(0.39 * 70)+(0.52 * 50)+(0.34 * 65)}{0.39+0.39+0.45+0.34}=64,46
$$

Dari hasil diatas terdapat tabel penilaian tingkat kepuasan pasien BPJS Kesehatan seperti pada tabel 1 dibawah ini.

Tabel 1 Penilaian Tingkat Kepuasan Pasien BPJS Kesehatan

\begin{tabular}{|c|c|c|}
\hline No & Keputusan & $\begin{array}{c}\text { Parameter } \\
\text { Nilai }\end{array}$ \\
\hline 1 & Kurang Puas & $0-40$ \\
\hline 2 & Puas & $41-79$ \\
\hline 3 & Sangat Puas & $80-100$ \\
\hline
\end{tabular}

Dari hasil perhitungan yang telah dilakukan, contoh kasus diatas memiliki hasil nilai defuzzy atau hasil nilai akhir 64,46 dan jika dipresentasekan menjadi $65 \%$. Maka pada kasus diatas Tingkat kepuasan pada pasien BPJS Kesehatan merasa Puas atas pelayanan perawatan kesehatan yang diberikan RSU. Martha Friska Multatuli Medan

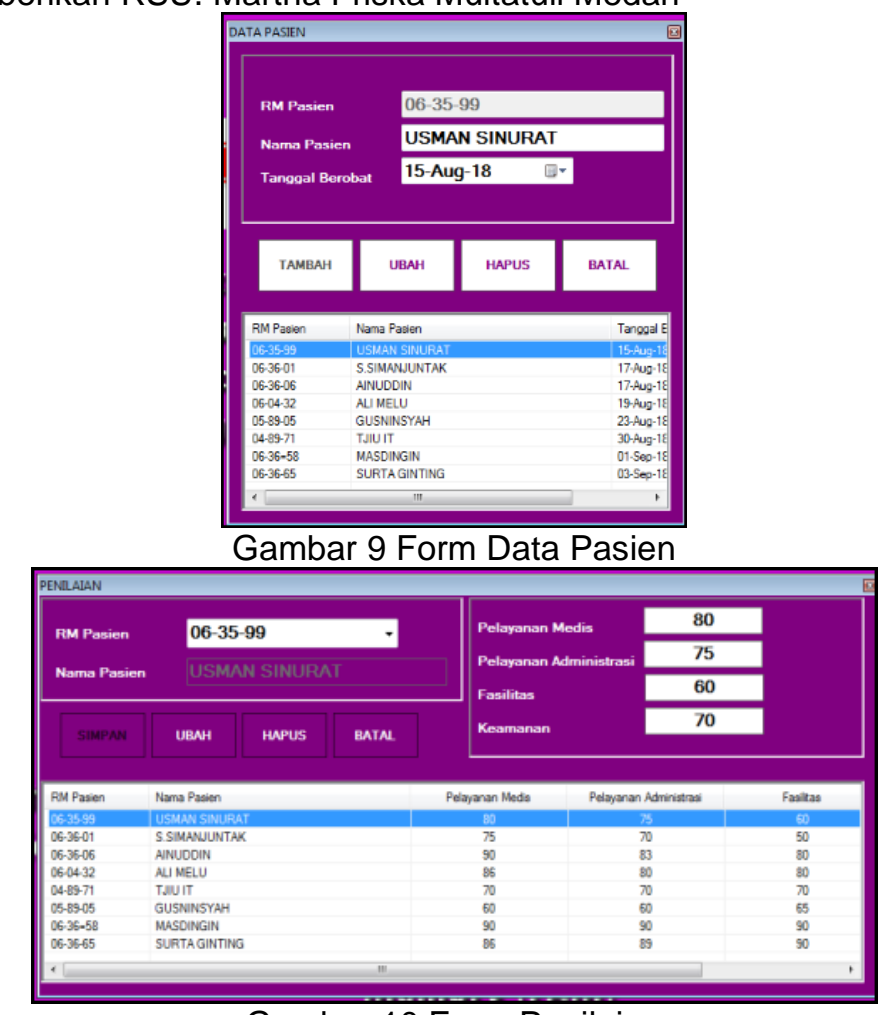

Gambar 10 Form Penilaian

J-SISKO TECH Vol. 3, No. 1, $2020: 70-77$ 


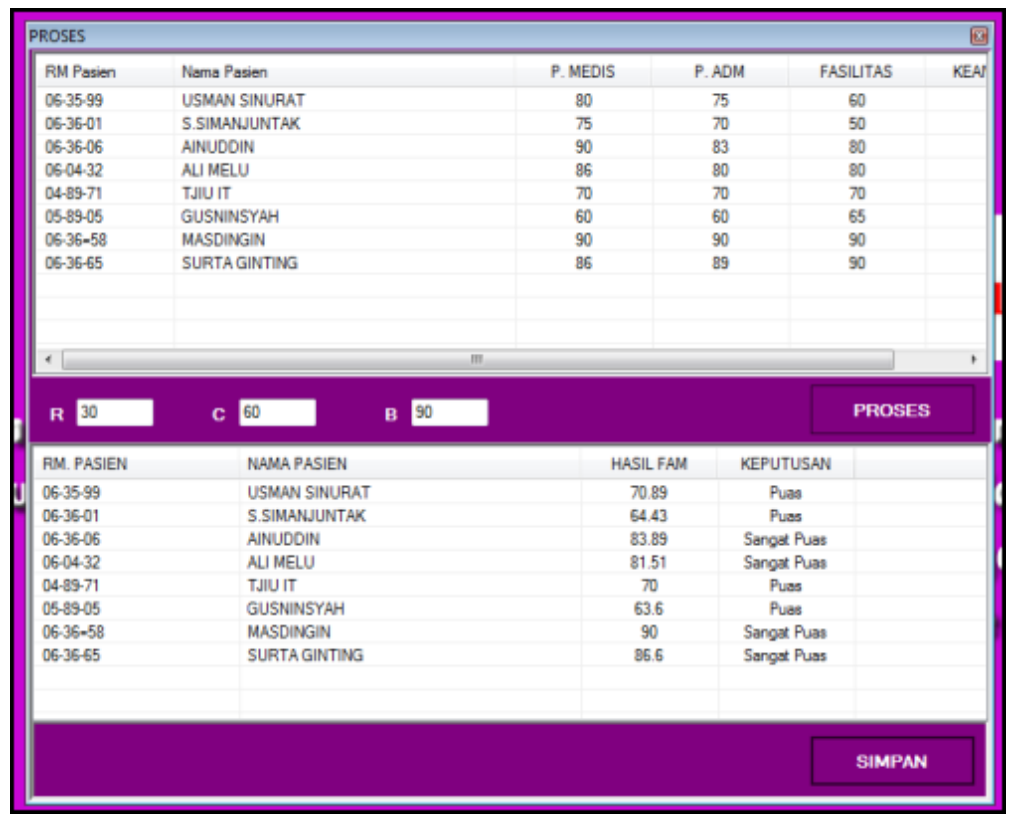

Gambar 11 Form Prose

\section{Kesimpulan}

Setelah melakukan analisa dan pengujian terhadap sistem, maka diambil beberapa kesimpulan diantaranya adalah sebagai berikut :

1. Sistem pendukung keputusan dapat digunakan dalam mengukur tingkat kepuasaan pasien BPJS Kesehatan terhadap pelayanan di RSU. Martha Friska Multatuli Medan.

2. Sistem pendukung keputusan dapat dirancang dalam mengukur tingkat kepuasan atas pelayanan di RSU. Martha Friska Multatuli Medan dengan menggunakan metode Fuzzy Associative Memory (FAM).

3. Sistem yang dirancang dengan metode Fuzzy Associative Memory (FAM) menghasilkan laporan tingkat kepuasaan pasien atas pelayanan di RSU. Martha Friska Multatuli Medan.

\section{DAFTAR PUSTAKA}

Hendrayudi (2010), Dasar-dasar pemograman Visual Basic 2008, YramaWidya: Bandung Hendrayudi. (2011). Dasar-dasar pemrograman Microsoft Visual Basic 2008. Bandung : PT. Sarana Tutorial Nurani Sejahtera.

Lusiana, K., Aris S., \& Helmi A (2013). Sistem Pendukung Keputusan Pemilihan Pengajar Les Privat Untuk Siswa Lembaga Bimbingan Belajar Dengan Metode AHP, Jurnal Masyarakat Informatika, 4(7), 2013,40

Nofriansyah, D. (2014). Konsep Data Mining VS Sistem Pendukung Keputusan. Yogyakarta : Deepublish.

Rossa A.S., M. Shalahuddin (2014). Rekayasa Perangkat Lunak Terstruktur dan Berorientasi Objek,

Informatika :Bandung

Sri K., \& Hari P., (2013). Aplikasi Logika Fuzzy untuk Pendukung Keputusan, Graha IImu: Yogjakarta 